\title{
Selective Adsorption of Cadmium Species onto Organic Clay Using Experimental and Geochemical Speciation Modeling Data
}

\author{
Mohamed Elmuntasir Ibrahim Ahmed
}

\begin{abstract}
The effect of cadmium speciation on cadmium adsorption onto Hexadethyl-trimethyl ammonium (HDTMA) modified montmorillonite was investigated experimentally and using Minteqa2 geochemical speciation model. The results revealed that the increase in cadmium uptake at higher $\mathrm{pH}$ values is selective and directly related to the nature of species present and that this increase does not affect the form of cadmium species adsorbed onto the HDTMA modified montmorillonite.
\end{abstract}

Index Terms-Adsorption, cadmium removal, cadmium speciation.

\section{INTRODUCTION}

Cadmium is a toxic heavy metal classified as a carcinogen and teratogen of significant environmental and occupational concern [1], [2]. It is present in different wastewater sources such as mining, smelting, electrolyzing, painting, alloying, electroplating, textile processing and printing, to name a few sources. Given the pervasive cadmium contamination and the low treatment standards [3], there is considerable interest in the development of techniques to remove cadmium from contaminated water and wastewater. Traditional methods for the removal and recovery of cadmium from industrial waste water are precipitation, ion exchange, electrolysis, and adsorption on activated carbon [4]-[7].

Adsorption has been developed as an efficient method for the removal of heavy metals from contaminated water and soil. A variety of adsorbents, including clays, zeolites, dried plant parts, agricultural waste biomass, biopolymers, metal oxides, microorganisms, sewage sludge, fly ash and activated carbon, have been used for cadmium removal [1], [8].

However, many techniques that have been used have their drawbacks and shortcomings. Use of large amounts of reagent and creation of second pollution are the flaws of precipitation method, while high cost is the main problem of the ion exchange method, membrane separation method and adsorption method by activated carbon.

Organo-clays have increasingly been used as adsorbents because they are cheaper than other materials such as activated carbon and zeolites. In many cases, organo-clay linings have been used as barriers in landfills to prevent contamination of groundwater and subsoil by leachates containing metals [9]. Bentonite and montmorillonite clays

Manuscript received May 11, 2014; revised August 23, 2014.

Mohamed Elmuntasir Ibrahim Ahmed is with the Kuwait Institute for Scientific Research, Kuwait (e-mail:miahmed@kisr.edu.kw). are usually chosen to avoid pollutant release into the environment as adsorbents due to their high specific surface areas, low cost and common presence in most soils [10].

Organo-clays are natural ion exchangers and adsorbents. They have a structure containing an excess of fixed negative or positive charge and take up ions from solution as needed to neutralize the charge. They can preferentially adsorb some types of ions relative to other ions; therefore the ratio between different counter-ions on an ion exchanger is usually not the same as the ratio between those ions in solution [11].

The type of clay is significant as its ability of clay to accumulate metals decreases, as seen in the following order: montmorillonite $>$ vermiculite $>$ illite $>$ chloride $>$ kaolinite $>$ [12]. In general it may be said that the greater the ability of clay to expand and effectively increase its surface area, the more metals it can accumulate. Clays can therefore contain considerable quantities of metals both on the surface and in between layers.

In an earlier paper [7] montmorillonite was modified with HDTMA to increase its surface area and pore size and hence its adsorptive capacity. The results revealed increased adsorption capacity of the modified montmorillonite for cadmium complexes in general and at higher $\mathrm{pH}$ values. Although this is advantageous for cadmium removal from contaminated water and wastewater, cadmium exists as a free divalent cation under common environmental conditions dominated by $\mathrm{pH}$ values up to 8 [7], [13]. Furthermore, in our previous investigations the adsorption isotherms were found to follow both Freundlich and Langmuir very well and showed slightly better fit with the latter isotherm [7].

These observations led to the identification of chemical reduction and surface precipitation as the limiting mechanisms for cadmium adsorption onto HDTMA modified montmorillonite.

In this paper, the limitations posed by cadmium speciation and the role speciation plays in cadmium adsorption onto the HDTMA modified montmorillonite are investigated using experimental results and geochemical equilibrium modeling.

\section{Methodology}

\section{A. Experimental Methods}

HDTMA modified montmorillonite was prepared by adding HDTMA to the full Cation Exchange Capacity (CEC) of the clay using the methodology described elsewhere [7].

Adsorption experiments were then conducted with cadmium using 200-ml flasks. Stock solution of cadmium 
was prepared and added to the desired initial concentrations. Cadmium concentrations were measured before and after each $\mathrm{pH}$ adjustment. In the case of controlled $\mathrm{pH}$ experiments, the $\mathrm{pH}$ was periodically checked during the adsorption process and adjusted using buffer solutions; a minimal headspace was allowed to insure good mixing throughout the adsorption experiment. The flasks were shaken in a Gyrotory shaker model G33-B positive rotary motion shaker $(250 \mathrm{rpm})$ for about 18 to $24 \mathrm{~h}$. Following the reaction period, the flasks were allowed to settle and samples were taken for analysis of residual aqueous concentrations. Phase separation was achieved by filtration using $0.45-\mu \mathrm{m}$ membrane filters.

Samples were analyzed for cadmium concentration using a multiple ion meter (pX meter) model 925 (Fisher Scientific), which measures $\mathrm{pH}$, voltage, temperature and ion concentration. The electrode used was an Orion combination electrode (sure-flow combination electrode model 9648), $\mathrm{pH}$ changes were accounted for with regard to the electrode potential behavior versus $\mathrm{pH}$ and limits of detection.

Prior to the measurement of concentrations, the samples were prepared in $50-\mathrm{ml}$ beakers after being filtered and adjusted for ionic strength. The ionic strength adjustment was done after the $\mathrm{pH}$ measurement, this is because the electrode performance depends solely on the use of ionic strength adjuster (5M NaNO 3 , model 940011).

\section{B. Geochemical Modeling}

A geochemical equilibrium model (MINTEQA2) [14] was used to study the speciation of cadmium $(30 \mathrm{mg} / \mathrm{l})$ solution leaving $\mathrm{pH}$ free and fixing the $\mathrm{pH}$ as desired.

\section{RESULTS AND DISCUSSION}

Organo-clays consist of composite layers of tetrahedrally and octahedrally coordinated cations. Layers of silica-oxygen tetrahedra are connected by cation-hydroxyl layers, the most common cations being aluminium ion and magnesium ion. Water molecules are also often found in between the layers [15].

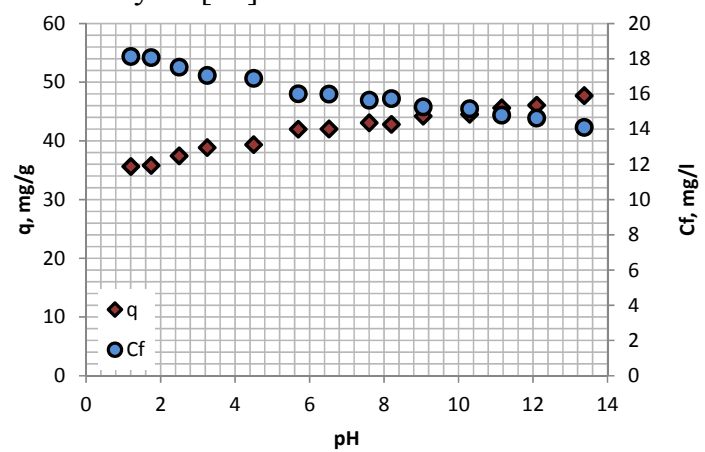

Fig. 1. Adsorption of cadmium onto modified montmorillionite as a function of $\mathrm{pH}$.

The clay minerals differ in their cation exchange properties according to the nature of their interlayer cations and residual surface charges. In clays, $\mathrm{Si}, \mathrm{Mg}$ and $\mathrm{Al}$ are often replaced by other cations with similar sizes but different charges. Thus, the surface of the clay can become negatively charged, which attracts more metal ions [16].

Adsorption of metals onto clays is influenced both by the number of free bonding sites on the clay surface and by the proportion of atoms replaced with others of different valencies in the clay. The $\mathrm{pH}$, the charge and the hydration of the metal species also influence adsorption.

Upon fully exchanging HDTMA the montmorillonite interlaminar structure changes and its pores becomes larger enabling a larger surface area and ability to accommodate larger metal molecules [17].

Fig. 1 shows an increased uptake of cadmium species as a function of $\mathrm{pH}$ and increased removal efficiency. This enhancement of adsorption at higher $\mathrm{pH}$ values indicates favorable adsorption of hydroxo-complexed cadmium ions for reasons related to the nature of adsorption process whether thermodynamic or chemical. This phenomenon is clear from the Minteqa 2 geochemical modeling results shown in Fig. 2.

(q) is the solid phase concentration and $\left(C_{f}\right)$ is the final cadmium concentration plotted on the secondary axis.

Fig. 2 shows the distribution of cadmium species with $\mathrm{pH}$. In the base case, the equilibrium $\mathrm{pH}$ was about 6.8 , and cadmium mostly exists as a free ion. When the $\mathrm{pH}$ was fixed at 12 , the speciation contained only hydroxyl species $(59 \%$ $\mathrm{CdOH}_{2}^{\circ}$ and $\left.40 \% \mathrm{CdOH}_{3}^{-}\right)$and no solids precipitated, and therefore at such low cadmium concentrations precipitation is not a removal mechanism [7]. Fig. 2 can be used to infer upon the quantities of hydroxocomplexes adsorbed and the nature of the adsorption process. At $\mathrm{pHs}$ up to 8 cadmium exists solely as a free ion, and the increase in adsorption capacity is attributed to clay behavior while at higher $\mathrm{pHs}(10,12)$ the formation of cadmium hydroxocomplexes increases significantly and surface reaction with clay may be the sole mechanism of adsorption as in the case of $\mathrm{pH} 12$.

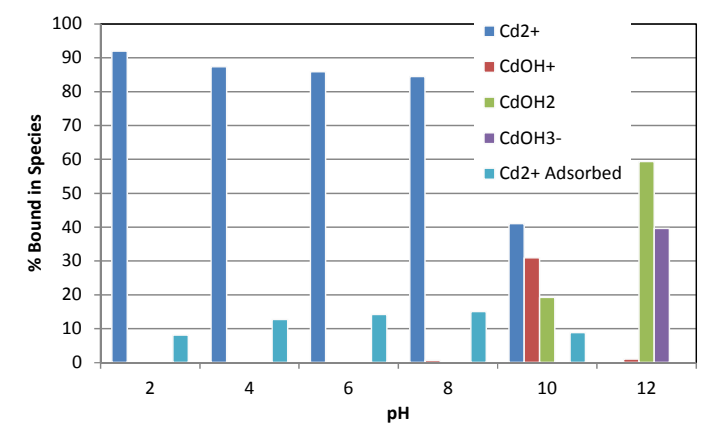

Fig. 2. Minteqa 2 speciation results of $150 \mathrm{ml}$ of $30 \mathrm{mg} / \mathrm{l} \mathrm{Cd}$ and $50 \mathrm{mg}$ modified clay.

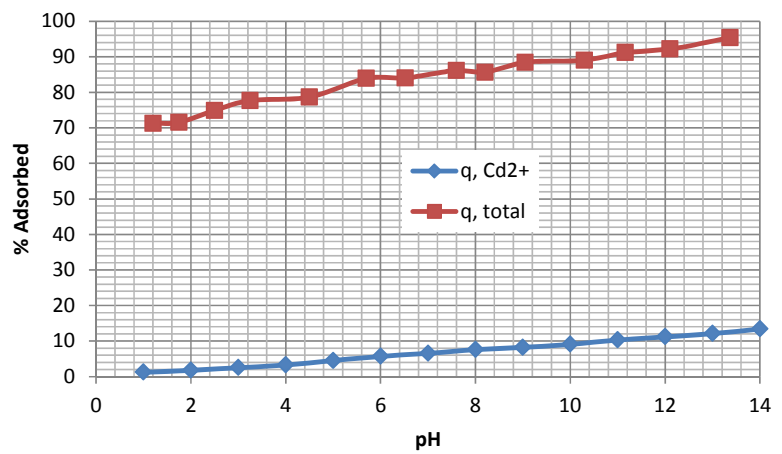

Fig. 3. Experimental percentage of total cadmium uptake from solution versus $\mathrm{pH}$ and the Minteqa 2 predicted divalent cadmium cation uptake percentage.

Fig. 3 reports the experimental total cadmium species adsorbed versus $\mathrm{pH}$ compared to the Minteqa 2 predicted 
adsorbed divalent cadmium ion. Although Minteqa 2 under predicted the adsorbed divalent free cadmium ion (as can be clearly seen from Fig. 2), it is also clear that the modified montmorillonite adsorption capacity increases with $\mathrm{pH}$ for all ions. Notwithstanding, the increase in capacity for both the free divalent ion and and the total cadmium is equal as can be seen in Fig. 3. These phenomena suggest that the uptake of cadmium onto modified montmorillonite is mostly thermodynamic and the final form of cadmium within the clay is the free divalent cation.

Due to the is amorphous substitutions in the aluminosilicate layers of the montmorillonite, it usually have a net negative charge, which is balanced by alkali metal and alkaline earth metal cations such as $\mathrm{Na}^{+}$and $\mathrm{Ca}^{2+}$. The strong hydration of these inorganic cations creates a hydrophilic environment on the surface and in the interlayer region of natural montmorillonite.

When these cations are replaced by organic cations, producing an organoclay structure, the montmorillonite clay becomes hydrophobic in character and can be used to remove hydrophilic and hydrophobic contaminants from water. The substitution of $\mathrm{Na}^{+}$or $\mathrm{Ca}^{2+}$ by quaternary ammonium cations (such as HDTMA) at the exchangeable sites of natural montmorillonite results in organoclay derivatives with organophilic properties that can act as sorbent for different contaminants.

It can be observed from the results that the adsorption of cadmium increases with increase in the $\mathrm{pH}$ of the solution. This is true regardless of the concentration of the solution investigated. Organo-clays are known to possess a negative surface charge in solution. As $\mathrm{pH}$ changes, surface charge also changes, and the sorption of charged species are affected (attraction between the positively charged metal ion and the negatively charged clay surface). It is conceivable that at low $\mathrm{pH}$ values, where there is an excess of $\mathrm{H}^{+}$ions in solution, a competition exists between the positively charged hydrogen ions and metal ions for the available adsorption sites on the negatively charged clay surface. As the $\mathrm{pH}$ increases and the balance between $\mathrm{H}^{+}$and $\mathrm{OH}^{-}$are more equal, more of the positively charged metal ions in solution are adsorbed onto the negative clay surface and thus the percentage removal of the metal ions increases.

This is in agreement with work by other authors [18]. On the other hand, precipitation of metal hydroxides may also occur as the $\mathrm{pH}$ in solution increases, which will lead to a corresponding decrease in the amount of metal ions adsorbed onto the clay but an increase in the overall removal efficiency. Our results are in agreement with these broad outlines.

In order to understand the adsorption mechanisms of cadmium species in relation to $\mathrm{pH}$, it is necessary to improve the knowledge of their behavior in the clay-solution system. The most important processes regulating the free concentration of heavy metals in natural media, such as the adsorption and release (desorption) by solid surfaces, highly depend on interfacial chemical reactions.

Generally, montmorillonite removes metals in variety of way [19]:

- Cation-exchange when the exchanged sites are available or when metal ions present in the clay are exchanged for metals in the solution.

- When the clays have high surface area it allows them to bind to a large number of metal species present in the solution.
- Organic matter in the clay can form complexes with metal species in the clay.

In all of these removal mechanisms the $\mathrm{pH}$ of the solution is an important variable which control the removal process and eventually the adsorption of the metal ion at the montmorillonite-solution interface.

Adsorption of heavy metals at montmorillonite-water interface can be described as surface complexation mechanism [21]. The uptake of heavy metals by clay minerals is obviously more complicated. The chemical nature of the metal clay interaction changes with increasing $\mathrm{pH}$ : at low $\mathrm{pH}$ values cation exchange is the dominating process [20], [22], whereas at high $\mathrm{pH}$ values, the uptake of heavy metal ions is accompanied by a release of hydrogen ions, and seems to be more specific than the uptake at low $\mathrm{pH}$ values. Thus, the classical ion exchange model does not cover the whole range of adsorption phenomena and a part of heavy metal adsorption occurs at sites created by displacement of protons from surface hydroxyls (i.e. surface complexation) [23].

Yan et al. [24] suggested that the effect of $\mathrm{pH}$ may be interpreted on the basis of availability of binding sites present at the clay surface and that the adsorption of free cadmium ion $\left(\mathrm{Cd}^{2+}\right)$ can be described by utilization of both ion-exchange sites and specific adsorption sites. At low $\mathrm{pH}$, $\mathrm{Cd}^{2+}$ is predominantly adsorbed on the permanent charge sites of $\mathrm{Na}+$ montmorillonite while substantial portion of $\mathrm{Cd}^{2+}$ was probably adsorbed on the edge surfaces at higher $\mathrm{pH}$ [25]. This may explain the increase of total cadmium adsorption at higher $\mathrm{pH}$ values in tandem with the increased interlayer spacing of the clay [26].

This is in agreement with Barbier et al. proposal that the uptake of heavy metal ions by montmorillonite from solution, from acidic to basic conditions can be describe by a model assuming two kinds of binding sites [27]:

- Ion exchange sites, $\mathrm{XNa}$;

- Specific adsorption sites, surface hydroxyl groups Al $(\mathrm{OH})(\mathrm{OH} 2)$, which are ampholitic.

Ion exchange seems to be the main sorption phenomena depending on the exchanged cation exchange capacity of the montmorillonite, but at low $\mathrm{pH}$ values, competition with protons is very important. Also, it appears that the HDTMA has higher ability to sorb cadmium oxyanion through exchange at the HDTMA positive charge sites.

Overall we can conclude that the increase in adsorption capacity of the modified montmorillonite is attributed to surface reaction with the cadmium species at the modified montmorillonite-solution interface. Additionally the free cadmium ion adsorption at higher $\mathrm{pH}$ values could be the result of ion-exchange process at the inner clay pores where ion-exchange sites have not been accessed and fully exchanged by the HDTMA.

\section{CONCLUSIONS}

The conclusions of this preliminary investigation are as follows:

1) Cadmium uptake onto HDTMA modified montmorillonite is $\mathrm{pH}$ dependent.

2) The mechanisms of uptake are of thermodynamic nature as the increase in uptake at higher $\mathrm{pH}$ values is related to 
the domination of different species than those at lower $\mathrm{pH}$ values.

\section{REFERENCES}

[1] H. K. Boparai, M. Joseph, and D. M. O'Carroll, Kinetics and thermodynamics of cadmium ion removal by adsorption onto nano zerovalent iron particles," Journal of Hazardous Materials, vol. 186, no. 1, pp. 458-465, 2011.

[2] M. P. Waalkes, "Cadmium carcinogens is in review," Journal Inorg. Biochem, vol. 79, pp. 241-244, 2010.

[3] WHO, Guidelines for Drinking Water Quality: Recommendations, 3rd ed., World Health Organisation, Geneva, vol. 1, 2008.

[4] M. M. Matlock, B. S. Howerton, K. R. Henke, and D. A. Atwood, "Apyridine-thiol ligand with multiple bonding sites for heavy metal precipitation," Journal Hazard. Mater, vol. 82, pp. 55-63, 2001.

[5] I. H. Lee, Y. C. Kuan, and J. M. Chern, "Factional experimental design for recovering heavy metal from sludge with ion-exchange resin," Journal Colloid Interface Science, vol. 333, pp. 46-53.

[6] H. T. Fan and P. R. Aderson, "Copper and cadmium removal by Mn oxide-coated granular activated carbon," Sep. Purifi. Technol., vol. 45, pp. 61-67, 2005.

[7] M. I. Ahmed, "Cadmium adsorption on HDTMA modified montmorillonite," Journal of Engineering Research, vol. 5, no. 1, pp. 104-110, 2007

[8] Y.C. Sharma, "Thermodynamics of removal of cadmium by adsorption on an indigenous clay," Chem. Eng. J., vol. 145, pp. 64-68, 2008.

[9] O. Abollino, M. M. Aceto, M. Malandrino, C. Sarzanini, and E. Mentasti, "Adsorption of heavy metals on Na-Montmorillonite. Effect of $\mathrm{pH}$ and organic substances," Water Research, vol. 37, pp. 1619-1627, 2003.

[10] V. Chantawong, "Adsorption of heavy metals by montmorillonite," in Proc. the Joint International Conference on Sustainable Energy and Environment (SEE), Hua Hin, Thailand, 2004.

[11] H. F. Hemond and E. J. Fechner, Chemical Fate and Transport in the Environment, Academic Press, San Diego, 1994.

[12] J. E. Fergusson, The Heavy Elements: Chemistry, Environmental Impact and Health Effects, Pergamon Press, Oxford, 1990.

[13] M. I. Ahmed, "Modified clays for the removal of cadmium from aqueous media," MSCE thesis, Bradley Universiy, Peoria, IL, USA, 1996.

[14] Allison Geoscience Consultants, Inc., and Hydro Geo Logic, Inc. MINTEQA2 for Windows Equilibrium Speciation Model version 1.50, Flowery Branch, GA, USA, 2003.

[15] J. Buffle and R. R. D. Vitre, Chemical and Biological Regulations of Aquatic Systems, Lewis Publishers, Boca Raton, 1994.

[16] W. A. Deer, R. A. Howie, and J. Zussman, An Introduction to the Rock Forming Minerals, Longman Scientific and Technical, Harlow, 1992.

[17] A. I. Jamrah and S. K. Dentel, "Application of organoclays to water treatment: selective removal of trichlorophenol," in Proc. the American Water Works Association (AWWA) Ann, San Antonio, 1993.

[18] P. P. Coetzee, L. L. Coetzee, R. Puka, and S. Mubenga, "Characterisation of selected south African clays for defluoridation of natural waters," Water SA, vol. 29, pp. 331-338, 2003.
[19] P. R. J. Smith. (2000). Use of A Glauconitic Clay to Remove Copper from Effluents Produced During Manufacture of Printed Circuit Boards. [Online]. Available: http://www.aecuk.com/PCB.html.

[20] L. Alberga, T. Holm, G. Tiravanti, and D. Petruzzelli, "Electrochemical determination of cadmium adsorption on kaolinite," Environ Technol, vol. 15, pp. 245-254, 1994.

[21] P. W. Schindler and W. Stumm, Aquatic Surface Chemistry, Wiley, New York, 1987.

[22] K. G. Tiller, J. Gerth, and G. Brummer, "The sorption of Cd, Zn, and Ni by soil clay fraction: procedures for partition of bound forms and their interpretation," Geoderma, vol. 34, pp. 1-16, 1984.

[23] M. Stadler and P. W. Schindler, "Modeling of H (super +) and cu (super $2+$ ) adsorption on calcium-montmorillonite," Clays Clay Miner, vol. 41, no. 6, pp. 288-296, 1993.

[24] L. Yan, X. Shan, B. Wen, and G. Owens, "Adsorption of cadmium onto A113-pillared acid-activated montmorillonite," Journal Hazard. Mater, vol. 156, pp. 499-508, 2008.

[25] U. K. Saha, S. Taniguchi, and K. Sakurai, "Adsorption Behavior of Cadmium, Zinc, and Lead on Hydroxyaluminum-and Hydroxyaluminosilicate-Montmorillonite Complexes," Soil Science Soc. Am. J., vol. 65, pp. 694-703, 2001.

[26] P. Wu, W. Wu, S. Li, N. Xing, N. Zhu, P. Li, J. Wu, C. Yang, and Z. Dang, "Removal of $\mathrm{Cd}^{2}+$ from aqueous solution by adsorption using Fe-montmorillonite," Journal Hazard. Mater, vol. 169, pp. 824-830, 2009.

[27] F. Barbier, G. Duc, and M. P. Ramel, "Adsorption of lead and cadmium ions from aqueous solution to the montmorillonite: water interface," Colloids Surf, A: Physicochem. Eng. Asp., vol. 166, pp. 153-159, 2000.

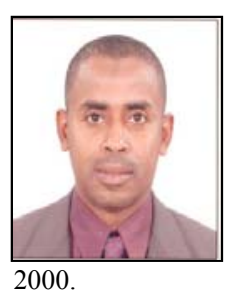

Mohamed Elmuntasir Ibrahim Ahmed was born in Khartoum, Sudan and he received his B.Sc. (honors) in civil engineering from the University of Khartoum, Khartoum, Sudan in 1992, he received his M.S. in civil engineering (environmental engineering) from Bradley University, Peoria, IL, USA in 1996, and he received his $\mathrm{Ph} . \mathrm{D}$. in environmental engineering from Illinois Institute of Technology (IIT), Chicago, IL, USA in

Currently, he is a research scientist at the Innovative Technologies for Wastewater Treatment and Reclamation (ITWTR) Program at Kuwait Institute for Scientific Research (KISR) in Kuwait. His experience include: international staff with $\mathrm{UN}$, regional staffs the Nile transboundary environmental action program, an associate professor at the University of Khartoum, Environmental Engineering Consultant with the University of Khartoum Consultancy Corporation, and a graduate research assistant at Illinois Institute of Technology. His research areas include low energy ion-exchange membrane processes, adsorption processes, hybrid biological processes for oil produced water treatment, Decision theory application for wastewater treatment plant operation, and environmental assessment.

Dr Ahmed is a fellow of the Sudanese Engineering Society. He was awarded Who's Who Among American Colleges and Universities (1997) and won many research grants. He has over 30 publications in international scientific journals and conferences. 